\title{
Numerical study of the effect of DSF walls geometrical shape on heat transfer
}

\author{
Mohamed Elamine GHEDHAB ${ }^{1,2 *}$, Ikram El ABBASSI ${ }^{1}$, Rafik ABSI ${ }^{l}$ and Yannick MÉLINGE ${ }^{2}$ \\ ${ }^{1}$ ECAM-EPMI, LR2E, 13 Boulevard de l'Hautil, 95092 Cergy-Pontoise, France \\ ${ }^{2}$ Université de Cergy-Pontoise, L2MGC, 5 Mail Gay-Lussac 95031 Cergy-Pontoise cedex, France.
}

\begin{abstract}
The building envelope is an important element that influences energy performance, both in terms of gains and losses. Indeed, much research has focused on improving and optimizing this element. The façade represents the main component of the envelope; it plays a crucial role lying in the protection of the internal environment of the building from external climate variations, by providing thermal comfort to its occupants. In order to gain in energy efficiency, a numerical investigation (CFD) on the influence of the geometric shape of façades on heat exchange in the building is carried out in this work. More particularly, the study will be established on double skin façades (DSF) representing the most commonly used facade typology on high-rise buildings. The simulations will be carried out taking into account the climate in Paris region. The first part will be dedicated to the definition of the basic model, which will be considered as a reference case with plan surfaces on the outside and inside of the building. In the second part, the influence of the shape of the external façade on heat exchange will be discussed.
\end{abstract}

Keywords:

Heat transfer, double skin façade, CFD simulation

\section{1) Introduction}

Conjugate heat transfer inside enclosures is a classical model used to study numerous engineering and physical phenomena, such as combustion engine, nuclear energy, food industry, solar systems and civil engineering [1]. To use this model in the building application, several experiences and numerical investigations were conducted in this last years, mixed natural convectionconduction were studied for different configurations, like double skin facades.

Many researches on the conjugate natural convection, conduction and radiation heat transfer has been done. Li et al. [2], studied the influence of the optical constants of semi-transparent wall on laminar natural convection, their study shown that the convective transfer decreases in the semi-transparent configuration compared to the opaque one. Xaman et al. [3] studied free convection combined with thermal radiation inside two-dimensional square cavity with a simple glass wall, they concluded that the flow is not symmetrical, this behaviour was explained by the fact that there is a temperature variation over the glass and the radiation interchange. GonzálezJulián et al. [4] investigated four cases of double panel window for a hot climate, taking into account the three heat transfer methods, results show that the configuration with a reflective treatment glass can reduce the heat flux passing this windows about $72 \%$ compared to the their reference configuration with à simple glass window.
Khatamifar et al. [5] examined the effects of partition position and thickness on the unsteady-state conjugate natural convection heat transfer in a differentially heated partitioned enclosure over a wide range of Rayleigh numbers, and found that when the thickness of the partition is increasing the average Nusselt number decreases. They also found that the position of the middle wall has a negligible effect on the Nusselt number. Liqun et al. [6] presented a two-dimensional analysis of turbulent combined convection radiation inside a divided enclosure with double semi-transparent walls, it was found that the transmittance has a great impact on the heat and flow characteristics inside the enclosure. Also it was concluded that the semitransparent walls reduce the heat losses.

This study is focused on the effect of geometrical shape of the external wall, for the double skin façade on rectangular enclosure. The aim of this configuration is to evaluate the temperature distribution in the internal environment when we modify the external semitransparent form. The present study is organised as follow: introduction is presented in section 1. Section 2 introduces the problem formulation. Numerical approach is described in the section 3 . In section 4, the results, analysis and discussion are reported. Finally, conclusion and future research areas are summarized in the section 5 .

\footnotetext{
*Corresponding author: m.ghedhab@ecam-epmi.com
} 


\section{2) Problem formulation}

The geometrical model configurations are shown in the figure 1, they represent two different shapes (case a and case b) of the external façades with two cavities in each case. The dimensions of the first and the second case are mentioned in the Table 1, the equivalent area of the cavity 1 is the same as of the case 1 . The considered fluid and solid materials are respectively the air and the glass, their thermo-physical properties are presented in Table 2.

The ambient temperature is $T_{a}=5^{\circ} \mathrm{C}$ with an external convective coefficient of $6.8 \mathrm{~W} / \mathrm{m}^{2} . \mathrm{K}$, which corresponds to a value of air velocity of $3 \mathrm{~m} / \mathrm{s}$ [3], the mean solar radiation ${ }^{\mathrm{a}}$ is $73 \mathrm{~W} / \mathrm{m}^{2}$, the inner temperature is fixed to $19^{\circ} \mathrm{C}$.
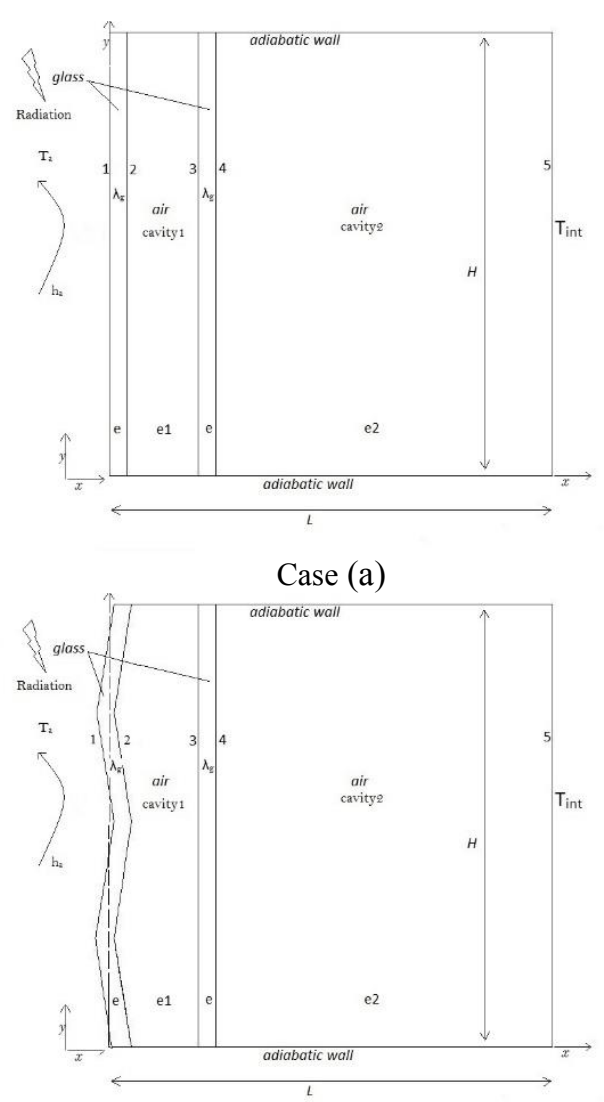

Case (b)

Fig 1. Schematic representations of the two studied cases

Tab 1. Geometrical dimensions

\begin{tabular}{|c|c|}
\hline $\mathbf{H}=\mathbf{L}[\mathbf{m m}]$ & 100 \\
\hline $\mathbf{e}[\mathbf{m m}]$ & 4 \\
\hline $\mathbf{e} 1[\mathbf{m m}]$ & 16 \\
\hline $\mathbf{e} 2[\mathbf{m m}]$ & $76 \mathrm{~mm}$ \\
\hline
\end{tabular}

${ }^{\mathrm{a}}$ and www.meteorange.fr
Tab 2. Thermo-physical properties

\begin{tabular}{|c|c|c|c|}
\hline & symbol & Air $\left(\mathbf{1 2}^{\circ} \mathbf{C}\right)$ & Glass \\
\hline Density & $\boldsymbol{\rho}\left[\mathbf{k g} / \mathbf{m}^{\mathbf{3}}\right]$ & 1.238 & 2500 \\
\hline Specific heat & $\mathbf{C p}[\mathbf{J} / \mathbf{k g} \cdot \mathbf{K}]$ & 1006 & 720 \\
\hline $\begin{array}{c}\text { Thermal } \\
\text { conductivity }\end{array}$ & $\lambda[\mathbf{W} / \mathbf{m} \cdot \mathbf{K}]$ & $2.454 \times 10^{-2}$ & 1 \\
\hline $\begin{array}{c}\text { Thermal } \\
\text { diffusivity }\end{array}$ & $\boldsymbol{\alpha}\left[\mathbf{m}^{2} / \mathbf{s}\right]$ & $1.944 \times 10^{-05}$ & - \\
\hline Viscosity & $\boldsymbol{\mu}[\mathbf{k g} / \mathbf{m} . \mathbf{s}]$ & $1.788 \times 10^{-05}$ & - \\
\hline Emissivity & $\boldsymbol{\varepsilon}$ & - & 0.85 \\
\hline Absorption coef. & $\mathbf{a}$ & - & 0.14 \\
\hline $\begin{array}{c}\text { Thermal } \\
\text { expansion coef }\end{array}$ & $\boldsymbol{\beta}[\mathbf{1} / \mathbf{K}]$ & $3.5069 \times 10^{-03}$ & \\
\hline Gravity & $\mathbf{g}\left[\mathbf{m} / \mathbf{s}^{\mathbf{2}}\right]$ & \multicolumn{2}{|c|}{9.81} \\
\hline
\end{tabular}

Assuming that the fluid is incompressible, Newtonian and the flow is in the steady-state and laminar, the fluid flow in both cavities is represented by the following 2D: continuity, momentum (Naviers-Stokes) and energy equations, taking into account the Boussinesq approximation for buoyancy forces, with the temperature equation in Cartesian coordinates presented as follow:

$\frac{\partial u}{\partial x}+\frac{\partial v}{\partial y}=0$

$u \frac{\partial u}{\partial x}+v \frac{\partial u}{\partial y}=\frac{1}{\rho}\left[-\frac{\partial p}{\partial x}+\mu\left(\frac{\partial^{2} u}{\partial x^{2}}+\frac{\partial^{2} u}{\partial y^{2}}\right)\right]$

$u \frac{\partial v}{\partial x}+v \frac{\partial v}{\partial y}=\frac{1}{\rho}\left[-\frac{\partial p}{\partial y}+\mu\left(\frac{\partial^{2} v}{\partial x^{2}}+\frac{\partial^{2} v}{\partial y^{2}}\right)+\rho g \beta \Delta T\right]$

$u \frac{\partial T}{\partial x}+v \frac{\partial T}{\partial y}=\alpha\left(\frac{\partial^{2} T}{\partial x^{2}}+\frac{\partial^{2} T}{\partial y^{2}}\right)$

Additionally, the boundary conditions are considered as: -No slip condition on walls surfaces $(\mathrm{u}=\mathrm{v}=0)$;

-Top and bottom walls are set as adiabatic $(\mathrm{q}=0)$;

-Wall 1: $\left(T_{1}-T_{a}\right) h_{a}+\sigma \varepsilon\left(T_{1}^{4}-T_{a}^{4}\right)=-\lambda_{g} \frac{\partial T_{g, 1-2}}{\partial x}$;

-Wall 2: $-\lambda_{g} \frac{\partial T_{g, 1-2}}{\partial x}=-\lambda \frac{\partial T}{\partial x}+q_{2, \text { rad }}+q_{2, \text { conv }}$;

-Wall 3: $-\lambda_{g} \frac{\partial T_{g, 3-4}}{\partial x}=-\lambda \frac{\partial T}{\partial x}+q_{3, \text { rad }}+q_{3, \text { conv }}$;

-Wall 4: $-\lambda_{g} \frac{\partial T_{g, 3-4}}{\partial x}=-\lambda \frac{\partial T}{\partial x}+q_{4, \text { rad }}+q_{4, \text { conv }}$;

-Wall 5: $\mathrm{T}_{5}=\mathrm{T}_{\text {int }}$.

\section{3) Numerical approach}

In this investigation, the governing equations are discretised by the finite volume method by using the solver Fluent V16.0. The SIMPLEC algorithm is chosen for the velocity-pressure coupling [7] [8]. The other discretization schemes are maintained in the second order and pressure-based solver is done by PRESTO. The Discrete Ordinates (DO) scheme is fixed in the first order [9].

In order to validate the proposed model, simple semitransparent wall's cavity is suggested to compare the obtained results with the numerical study of Xaman [3]. 
To this end, The Rayleigh number is estimated to $10^{6}$ inside the enclosure. Figure 2 illustrates the dimensionless temperature distribution at mid-height of the cavity compared to Xamán et al. simulations for $\mathrm{Ra}=10^{6}[3]$.

$$
X^{*}=\frac{x-e_{1}}{L} \quad T^{*}=\frac{T-T_{2}}{T_{\text {int }}-T_{2}}
$$

Where $T_{2}$ is the temperature in interface 2 .

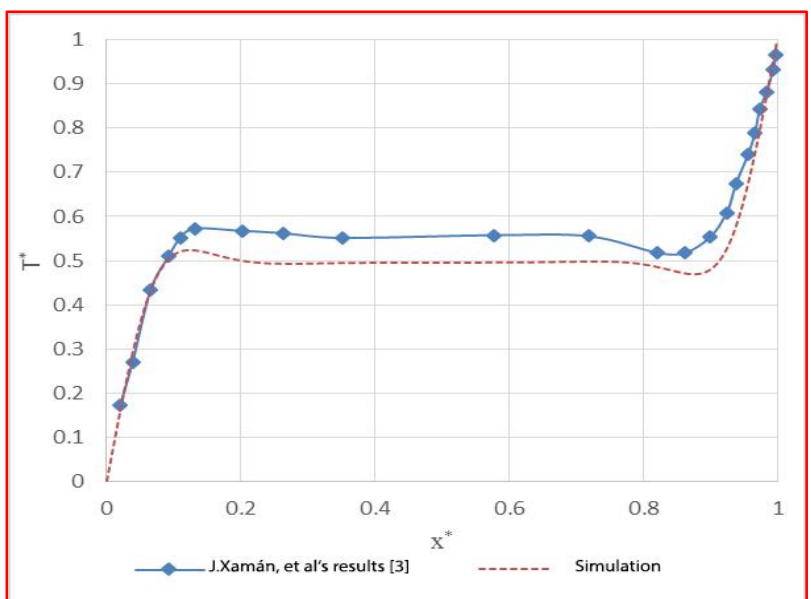

Fig 2. Dimensionless temperature at mid-high of cavity

\section{4) Results and discussion}

The simulations are performed taking into consideration the data climate of Paris region ${ }^{b}$. The mesh used for the first configuration has a rectangular form with equal sizes in the $x$ and $y$-axis $\left(\Delta x=\Delta y=8 \times 10^{-4} \mathrm{~m}\right)$. For both cases, previously presented in Figure 1, the value of the Rayleigh number is $\mathrm{Ra} \approx 3 \times 10^{5}$ for each case of the second cavity.

Figure 3 represents the temperature profile in the internal surface 4 of the internal wall for the two cases.

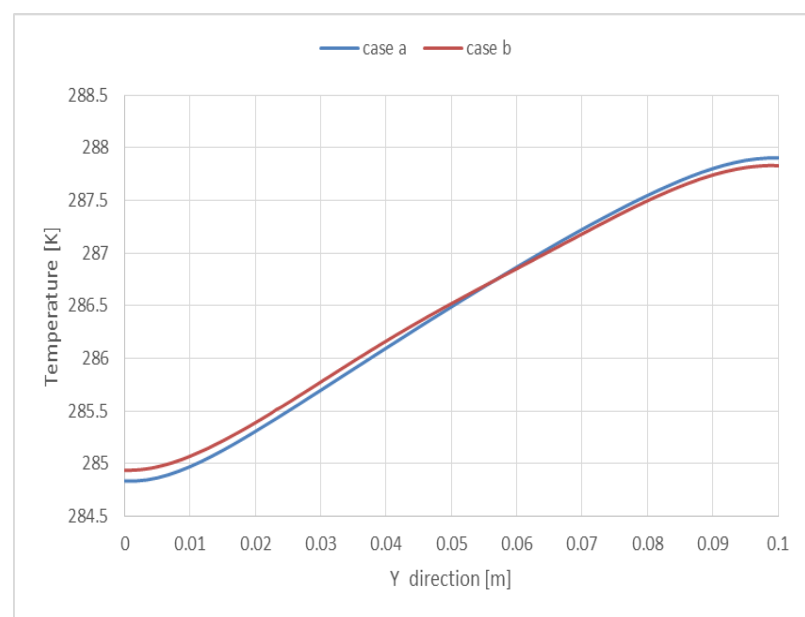

Fig 3. Temperature distribution in the surface 4

\footnotetext{
${ }^{\mathrm{b}}$ www.climate-data.org
}
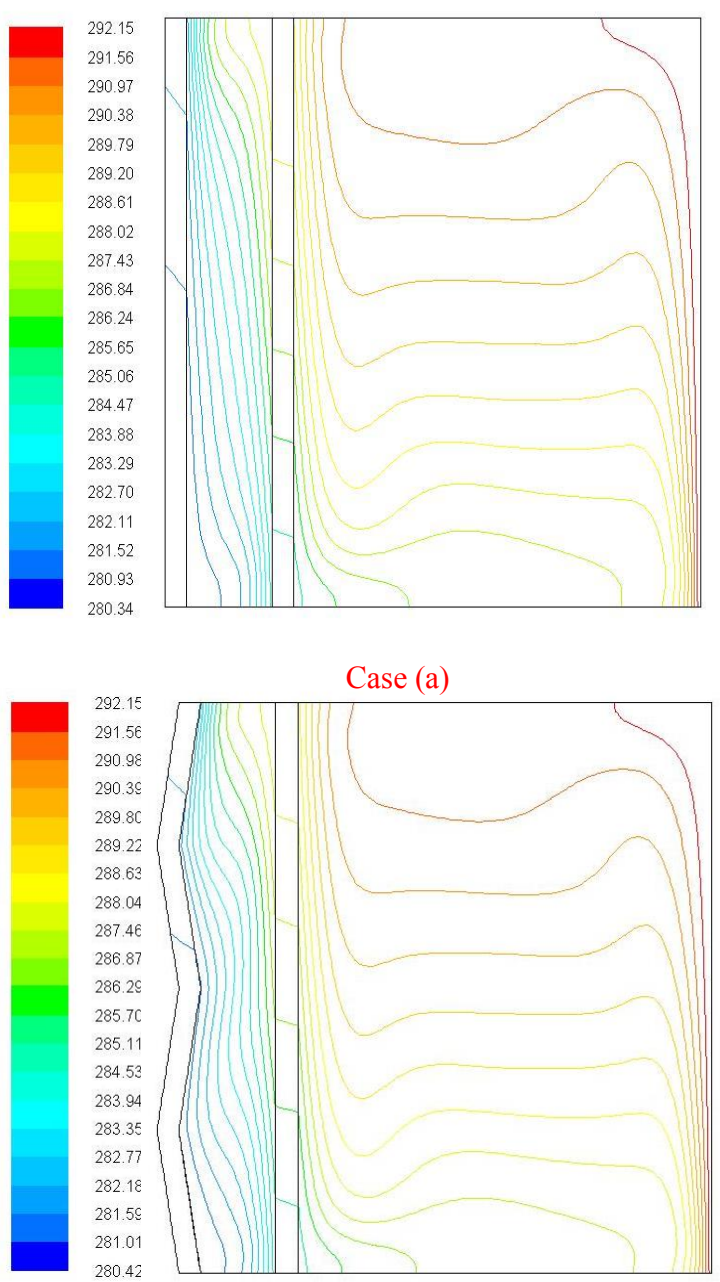

Case (b)

Fig 4. Isothermal contours

The results show that the temperature profiles are symmetrical with the mean value, but there is a small difference between the two cases. In case (b) the temperature is higher in the bottom and lower on the top compared to case (a). This involves a lower mean temperature in case (b) with the proposed modified geometry (figure 3 ).

According to figure 4, it can be clearly seen that the isothermal contours have not a considerable variation. However, refereeing to the colormaps, the value of the temperature in case (b) is lower than the value in case (a) in term of the mean temperature. More analysis is needed since external surfaces and external heat convective coefficients are not the same in the two cases.

Knowing that a common colormaps scale is used to evaluate the slight difference in the stream function contours, it can be observed through figure 5 that the values of the stream function of case (a) are greater than in case (b) in both cavities. This means that the flow is weak in the enclosure with the modified external wall. 

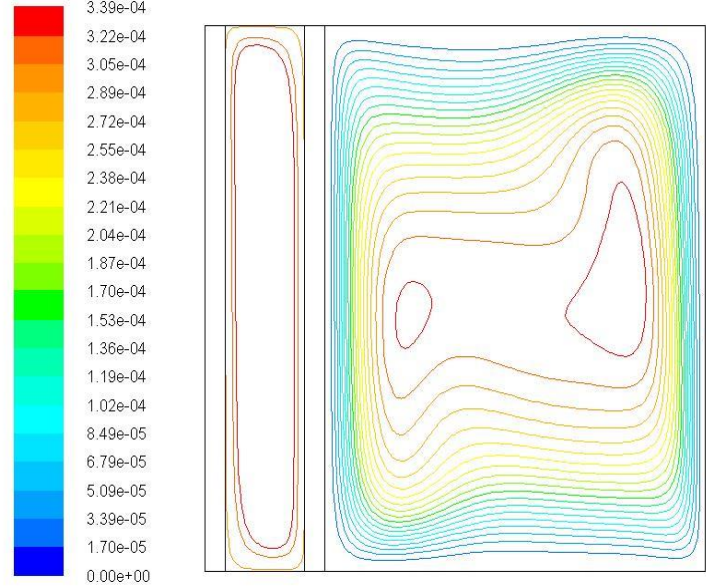

Case (a)

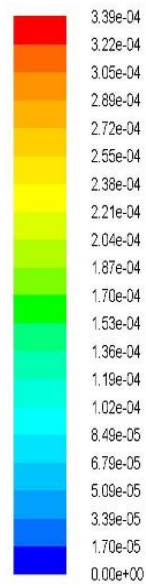

$3.39 e-04$
$3.22 e-04$
$3.05 e-04$
$2.89 e-04$
$2.72 \mathrm{e}-04$
$2.55 \mathrm{e}-04$
$2.38 \mathrm{e}-04$
$2.21 \mathrm{e}-04$
$2.04 \mathrm{e}-04$
$1.87 \mathrm{e}-04$
$1.70 \mathrm{e}-04$
$1.53 \mathrm{e}-04$
$1.36 \mathrm{e}-04$
$1.19 \mathrm{e}-04$
$1.02 \mathrm{e}-04$
$8.49 \mathrm{e}-05$
$6.79 \mathrm{e}-05$
$5.09 \mathrm{e}-05$
$3.39 \mathrm{e}-05$
$1.70 \mathrm{e}-05$
$0.00 \mathrm{e}+00$

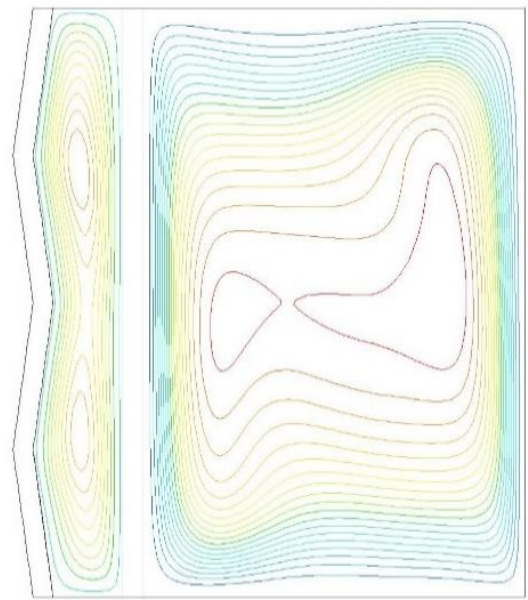

Case (b)

Fig 5. Stream-function contours

\section{5) Conclusion and perspectives}

In this work, a numerical study has been conducted for a double skin façade configuration so as to evaluate the effect of external shape on the thermal transfer and inside environment flow pattern. The obtained results show that the bottom and top temperatures on the indoor surface of the internal wall are impacted (when the geometry is different), we observed that the temperature difference values are small between the convectional and proposed geometry. This difference could be related to the considered small scale of our cases compared to the real building dimensions on the one hand and to the flow regime on the other hand. Additionally, we took the same value for the convective coefficient in both cases. However, this value should be different when the external surface is modified (case b). This will be considered in our future simulations. Simulations are currently being carried out with realistic dimensions corresponding to real building configurations in order to provide practical solutions for architects and civil engineers in term of thermal comfort.

\section{References}

[1] A.Baïri, E.Zarco-Pernia and J.-M. d. María, Applied Thermal Engineering, 63, 304-322, 2014.

[2] D. Li, Q. Ai, X. Xia and G. Wu, International Journal of Heat and Mass Transfer, 67, 724-733, 2013.

[3] J.Xamán, J.Arce, G.Álvarez and Y.Chávez, " International Journal of Thermal Sciences, 47(12), 1630-1638, 2008.

[4] E.González-Julián, J.Xamán, N. O.Moraga, Y.Chávez, I.Zavala-Guillén and E.Simá, Applied Thermal Engineering, 143, 100-111, 2018.

[5] M. Khatamifar, . W. Lin, S. Armfield, D. Holmes and M. Kirkpatrick, International Communications in Heat and Mass Transfer, 81, 92-103, 2017.

[6] Z. Liqun, L. Jiaying, H. Qunwu and W. Yiping, Transactions of Tianjin University, 25(5), 472-487, 2019.

[7] R. Absi, in Proc. 27th International Conference on Coastal Engineering (ICCE), July 16-21, 2000, Sydney, Australia, 2000.

[8] N. El-Gharbi, R. Absi and A. Benzaoui, J. Appl. Fluid Mech., 5, 63-70, 2012.

[9] "ANSYS Fluent User's Guide, Release 15.0. 2620 p.," ANSYS INC, 2013. 